\title{
A narrative review of Poland's syndrome: theories of its genesis, evolution and its diagnosis and treatment
}

\author{
Eman Awadh Abduladheem Hashim ${ }^{1,2} \wedge$, Bin Huey Quek ${ }^{1,3,4}$, Suresh Chandran ${ }^{1,3,4,5} \wedge$ \\ ${ }^{1}$ Department of Neonatology, KK Women's and Children's Hospital, Singapore, Singapore; ${ }^{2}$ Department of Neonatology, Salmanya Medical Complex, \\ Manama, Kingdom of Bahrain; ${ }^{3}$ Department of Neonatology, Duke-NUS Medical School, Singapore, Singapore; ${ }^{4}$ Department of Neonatology, NUS Yong \\ Loo Lin School of Medicine, Singapore, Singapore; ${ }^{5}$ Department of Neonatology, NTU Lee Kong Chian School of Medicine, Singapore, Singapore \\ Contributions: (I) Conception and design: EAA Hashim, S Chandran; (II) Administrative support: S Chandran, BH Quek; (III) Provision of study \\ materials: EAA Hashim, S Chandran; (IV) Collection and assembly: All authors; (V) Data analysis and interpretation: BH Quek, S Chandran; (VI) \\ Manuscript writing: All authors; (VII) Final approval of manuscript: All authors. \\ Correspondence to: A/Prof. Suresh Chandran. Senior Consultant, Department of Neonatology, KK Women's and Children's Hospital, Singapore \\ 229899, Singapore. Email: suresh.chandran@singhealth.com.sg.
}

\begin{abstract}
Poland's syndrome (PS) is a rare musculoskeletal congenital anomaly with a wide spectrum of presentations. It is typically characterized by hypoplasia or aplasia of pectoral muscles, mammary hypoplasia and variably associated ipsilateral limb anomalies. Limb defects can vary in severity, ranging from syndactyly to phocomelia. Most cases are sporadic but familial cases with intrafamilial variability have been reported. Several theories have been proposed regarding the genesis of PS. Vascular disruption theory, "the subclavian artery supply disruption sequence" (SASDS) remains the most accepted pathogenic mechanism. Clinical presentations can vary in severity from syndactyly to phocomelia in the limbs and in the thorax, rib defects to severe chest wall anomalies with impaired lung function. Most patients have subtle presentation at birth and milder forms in childhood. Functional limitations due to PS are usually minimal. Surgical treatment aims to improve pulmonary functions arising from severe thoracic deformities but is more often done to enhance the cosmesis. The use of adipose-derived mesenchymal stem cells and fat transfer have shown promising results in recent times for correction of chest defects and breast augmentation. Gaining deeper insights into the etiopathogenesis and clinical presentation of PS will improve the clinical recognition and management of this rare condition. In this review article, we aim to outline the details of this syndrome including its etiopathogenesis, evolution, spectrum of clinical manifestations, other systemic associations, diagnostic modalities, and recent advances in treatment.
\end{abstract}

Keywords: Poland's syndrome (PS); pectoralis muscle hypoplasia; vascular disruption sequence; breast hypoplasia; brachysyndactyly

Submitted Oct 05, 2020. Accepted for publication Jan 29, 2021.

doi: $10.21037 / \mathrm{tp}-20-320$

View this article at: http://dx.doi.org/10.21037/tp-20-320

\section{Introduction}

In his autopsy report, Alfred Poland expounded the "deficiency of pectoral muscles" as deficient sternal and costal portions of the pectoralis major muscle and absence of pectoralis minor muscle in addition to brachysyndactyly of the ipsilateral hand, underdeveloped serratus anterior muscle and remarkably small thoracic vessels $(1,2)$. Absence of the sternal head of pectoralis major muscle is an essential feature of Poland's syndrome (PS) and most

^ORCID: Eman Awadh Abduladheem Hashim, 0000-0002-4402-5301; Bin Huey Quek, 0000-0001-8891-5464; Suresh Chandran, 00000001-5961-7441. 
often it manifests also as ipsilateral thoracic cage and upper limb anomalies. Other recognized features of PS include aplasia/hypoplasia of the pectoralis minor muscle and breast/nipple, rib anomalies, dextrocardia, urogenital anomalies and axillary alopecia (3). Clinical features of PS are phenotypically variable and manifestations are often subtle in infancy and early childhood delaying the diagnosis and plan for intervention. This review aims to improve the understanding of PS among medical fraternity about its genesis, spectrum of clinical manifestations, diagnostic tools and recent advances in therapeutic modalities.

We extensively relied upon Medline and EMBASE database search to obtain relevant papers and their cited references, in addition to our personal clinical experience and publications of PS with lung herniation and eventration of diaphragm to prepare this review (4). We present the following article in accordance with the Narrative Review reporting checklist (available at http://dx.doi.org/10.21037/ tp-20-320).

\section{Historical perspective}

PS was first described by Alfred Poland nearly 180 years ago based on an autopsy at Guy's Hospital of a 27-yearold ex-convict named George Elt (1). Several depictions about this musculoskeletal anomaly similar to that of Alfred Poland's autopsy record predated the official publication in Guy's Hospital Reports [1841]. On $11^{\text {th }}$ December 1803, "Citizen Marandel" presented in the second session of the Société Anatomique de Paris a description of a woman with congenital mammary absence and muscular atrophy (sternohumeral and costo-coracoid) on the right side, similar to the observations of Poland $(5,6)$. Absence of pectoral muscles alone was described earlier (7). In 1839, Froriep was the first to describe the paired absence of pectoral muscles and webbed digits (8). Even though Alfred Poland described the characteristics of this syndrome, it was Patrick Clarkson, a plastic and hand surgeon working at Guy's Hospital, London, who coined the term "Poland's syndactyly" (2). Clarkson noted a clear description of this paired deformity in a review by Brown \& McDowell who referred to Poland's original report (9). Clarkson also retrieved the dissected specimen of the hand by Poland from the Curator of the Gordon Museum and confirmed the syndactyly between the index and middle finger. Later, McDowell criticized the eponym and argued that "Poland hadn't the foggiest notion that the two deformities constituted a syndrome" because Tilston's sketch of the dissected cadaver by Poland omitted the forearm and hand (10). Later it was Thompson who identified the principal features of PS and summarized the complete spectrum of congenital anomalies (11). Baudinne et al. referred to Poland's syndactyly as PS (12). Controversy remains around the eponymous origin of PS $(6,13)$.

\section{Etiopathogenesis}

Researchers have been debating on the etiology of PS for more than three decades. Several theories and etiological factors have been suggested. Being a congenital disorder, birth defects occur due to an error in morphogenesis resulting in malformations, deformations, or disruptions. Embryonic or fetal vascular disruption can cause disruption sequences and the incidence was reported to be $0.1 / 1,000$ infants born with more than one structural anomaly (14). Vascular disruption theory remains the most accepted pathogenic mechanism. The likely pathogenesis of PS may be due to disruption of development of the proximal subclavian artery and its branches that supply the pectoral muscles around $6^{\text {th }}$ week of gestation. This further leads to deficient blood flow to the distal limb and pectoral region causing regional loss of tissue. Bavinck \& Weaver presented a pathogenic hypothesis and introduced the term called "the subclavian artery supply disruption sequence" (SASDS) to describe the disruption of embryonic vessels, suggesting a common pathogenesis in PS, Klippel-Feil and Moebius syndromes (15). Predictable patterns of defects as a consequence of SASDS were described as follows:

* Absence of pectoralis major and ipsilateral breast hypoplasia due to interruption of internal thoracic artery flow.

* Terminal transverse limb defect following a disruption of subclavian artery distal to the origin of internal thoracic artery.

* PS resulting from a disruption of subclavian artery distal to the origin of the vertebral artery but proximal to the origin of internal thoracic artery.

* Klippel-Feil syndrome caused by an interruption of blood flow through entire length or segments of vertebral arteries.

* Moebius syndrome resulting from early regression of the primitive trigeminal arteries and/or delayed formation of or obstruction in basilar and/or vertebral arteries.

Data of decreased size and low velocity flow of subclavian artery in PS supports SASDS theory (16). More evidence in support of SASDS theory was noted in a 4-year-old girl 
with below knee right leg hypoplasia and ipsilateral toe brachysyndactyly. Her Doppler evaluation revealed 50\% reduction in femoral artery blood flow (17). Atasoy et al. has suggested that in a boy with PS, SASDS could have caused the manifestations due to thrombosis of the fetal microvasculature as they detected significant mutations in his thrombophilia genes (homozygote A1298C MTHFR, heterozygote Factor V H1299R, and Factor II G20210A mutations) (18).

Several factors, including mechanical, environmental, and embryologic events can cause interruption or reduction in blood flow to the subclavian artery and its branches. Intrinsic factors like thrombi and emboli, or external mechanical factors like cervical rib, aberrant muscle, amniotic bands can cause vascular disruption $(14,19,20)$. Extrinsic events, such as the first rib and cervical rib can force the U-shaped configuration of the subclavian artery into a defective configuration, leaving the artery hypoplastic $(14,21)$. Other suggested hypotheses include maternal factors, such as smoking and cocaine abuse (22). Smoking in pregnancy has shown a two-fold risk of developing PS in Hungary and Spain (23). However, a case report of a 17-year-old with significant left pectoral muscle deficiency with no arterial alteration has raised questions against the SASDS theory for pathogenesis of PS (24).

Genetic or extrinsic factors may interfere with the pectoralis major muscle migration and digital separation, both occurring between 6 to 8 weeks of gestation $(25,26)$. Although, most of the PS cases are sporadic, familial cases have been reported. Familial PS raises the question of an autosomal dominant mode of inheritance with variable penetrance. These familial cases showed intra-familial variability (27-29). This clinical variability and bilateral features seen in some cases of PS could be explained by paradominant inheritance $(30,31)$.

Lately, a de novo mutation of chromosome 11q12.3 in monozygotic twins with PS was reported. The twins had heterozygous deletion in genes which controlled cellular growth, differentiation and apoptosis, which authors postulate to be causative of PS. Phenotype concordance between the female monozygotic twins shed light on this mutational role in the genesis of PS (26).

Duplication in the region between 10p13 and 10p14 has been reported recently in an infant with congenital hyperinsulinism (CHI) and PS phenotype. Authors hypothesized that the duplication in the region between $10 \mathrm{p} 13$ and 10p14 involving UCMA (upper zone of growth plate and cartilage matrix associated), which control osteogenic differentiation of fetal cartilage and cartilagebone interface could contribute to PS phenotype. Also, an increase in hexokinase activity (HK1) with 10p duplication is known to cause CHI (32).

Association of renal with pectoralis major/minor malformations in PS has been linked to acro-renal polytopic field defect. In the embryonic stage of $6-7^{\text {th }}$ week, pectoralis mesenchyme separates into pectoralis major and minor and simultaneously metanephros appears following regression of mesonephros. It was speculated that an insult at this stage of embryogenesis can cause both pectoral and renal anomalies $(27,33)$. Circumscribed disruption of lateral embryonic plate mesoderm causing PS was suggested in an infant with limb body wall defect $(27,34)$.

\section{Epidemiology}

PS occurs in about 1:30,000 live births (35). Incidence variations have been reported in the past, ranging from around 1 in 17,000 live births in Japan and a comparatively lower incidence of 1 in 52,530 live births in Hungary (20). But no studies have examined ethnicity as an underlying factor for this variation. Incidentally, PS has been diagnosed in 1 of every 19,000 mammograms done during 1985-1995 (36). Poland syndrome is more often seen in males than females $(3: 1)$ and involves more frequently the right side of the body than the left, in a ratio of 1.7:1 (37). In sporadic forms, there is male predominance with the right side more affected than the left but in females both sides are equally affected. In familial forms, both sexes are affected equally, and no rightside predominance has been reported $(15,36)$. Bilateral PS was reported in a young female with bilateral absence of breasts, right pectoral aplasia and absent right ulna and ulnar side of the hand (38). Since then, 15 cases of bilateral PS have been reported in the literature (39).

\section{Clinical spectrum}

The characteristic features of PS include unilateral hypoplasia/aplasia of the pectoralis major/minor muscles (Figure 1) with variable degree of ipsilateral upper limb anomalies $(1,2)$. Less often, varying degrees of hypoplasia of latissimus dorsi, deltoid, serratus anterior, supraspinatus, infraspinatus and external oblique muscles have been noted. Breast asymmetry to amastia was also reported in more than a third of female subjects with PS (40). Often, the nipple and areola are hypoplastic, less pigmented and elevated. Incidences of athelia and supernumerary nipples although 


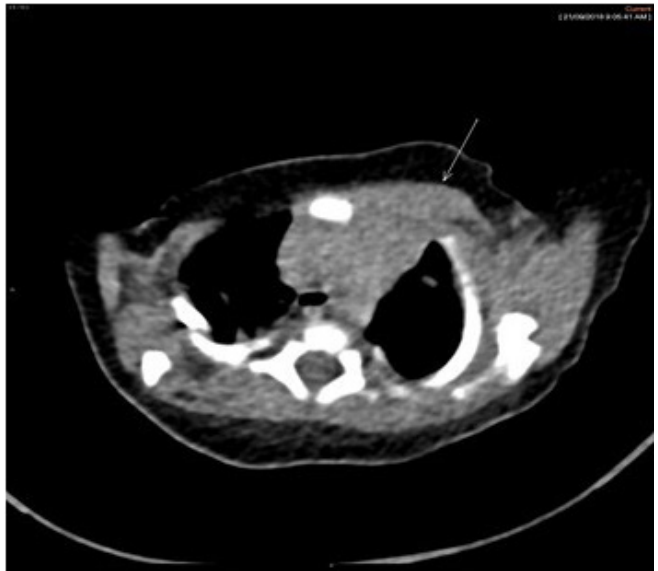

Figure 1 Axial CT image shows the normal left pectoralis major muscle (arrow). The right pectoralis major muscle is not seen on the opposite side of the chest.

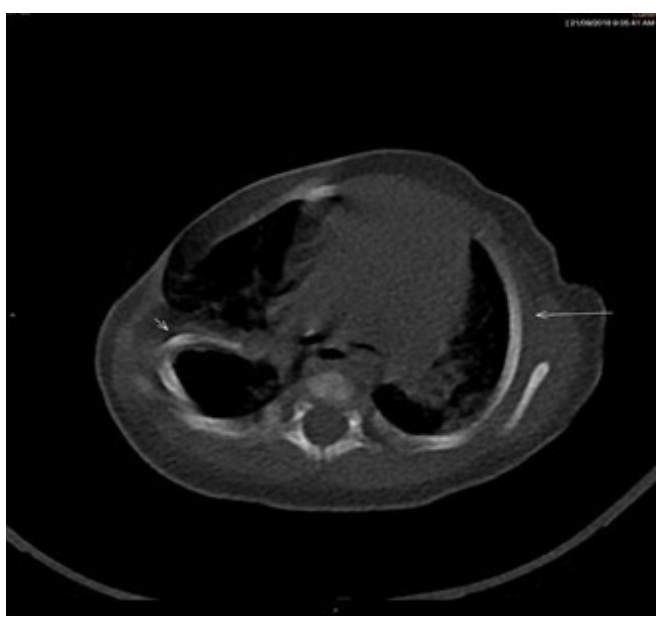

Figure 2 Axial CT image shows the normal left rib (long arrow). The corresponding right rib is short compared to the left (short arrow).

rare, have also been reported (41).

Chest deformities observed in PS includes a keeled chest (9.7\%), followed by hollowed chest (0.8\%) (42). Hypoplasia of the ribs and cartilages leaves a sunken chest wall on the affected side. Rib defects are reported in $18 \%$ in rightsided compared to $40 \%$ in left-sided PS (43) (Figure 2). Hypoplasia or aplasia occurs more often in second to fourth or third to fifth ribs and cartilages, but the second rib is less frequently affected (40). Bifid (forked) rib is rare (2\%) and scoliosis has been reported in $1.7 \%$ of cases with PS. The chest deformities progress rapidly during growth spurt and fusion of the aplastic ribs may give an appearance of asymmetrical contralateral pectus carinatum due to sternal rotation to the affected side. Severe rib anomalies can result in respiratory dysfunction $(42,44-46)$.

In either gender with apparent PS, anterior axillary fold is poorly formed due to aplasia or hypoplasia of the pectoralis major muscle and the posterior fold formed by latissimus dorsi and teres major muscles is visible from the front. Hand-pectoral deformity in PS involves the ipsilateral hand abnormalities, which can vary from syndactyly or symbrachydactyly (89\%), short middle phalanges (45\%) to rarely ectrodactyly. Hypoplasia of the middle phalanges with cutaneous webbing need not be restricted to digits that are involved in syndactyly and are more often reported in middle phalanges of ulnar side of the hand than radial (47). Varying degrees of hypoplasia of the upper extremity involving the wrist and hand (89\%), forearm (37\%), arm $(7 \%)$ and rarely phocomelia-like deficiency has been reported $(27,48)$.

Distortions in digital dermatoglyphics in two cases of PS were reported and since then several authors have attempted to link PS and dermatoglyphics (49-51). Freire-Maia et al. observed zygodactylous triradii associated with a loop, distally placed axial triradii and simian lines in the affected hands of two cases of PS (52). Atasu also reported similar findings in his four cases of PS (53). Characteristic chest and limb defects of PS with abnormal dermatoglyphics were reported in a 10-year-old boy (54).

Involvement of lower extremity is rare in PS (17). Unilateral gluteal and lower limb hypoplasia with toe symbrachydactyly was reported with possible disruption of external iliac artery supply $(55,56)$. A Japanese woman with PS who had absent right pectoralis major, hypoplastic rib cage, underdeveloped breast, short sternum, and scoliosis also had hypoplasia of the right ilium and gluteus minimus and atrophied right kidney. Contrast CT scan showed disruption of the right internal iliac artery (57).

Lung herniation (9\%) is rare in PS. In some patients with rib defects, lung herniation occurs only during episodes of respiratory infection but rarely can occur during normal breathing/crying in newborn infants with PS $(4,58)$ (Figures 3,4) (Video 1). Chest radiograph may reveal hyperlucent lung fields on the affected side with heart displaced towards the unaffected side (4). Isolated dextrocardia was reported in PS with a frequency of 1 in 30,000 live births (59). A strong association of dextrocardia with partial agenesis of 2 or more ribs was observed and none had congenital heart disease (43). Eventration of diaphragm with PS is a rare 


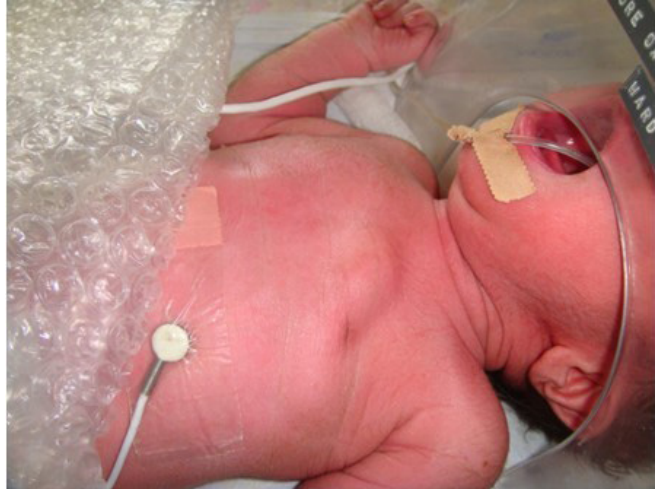

Figure 3 Infant with Poland's syndrome showing the lung herniation on expiration. (Reproduced from Lung herniation: an uncommon presentation of Poland's syndrome in a neonate at birth. Chandran S, et al. BMF Case Rep. 2013 Aug 6;2013, with permission from BMJ Publishing Group Ltd.).

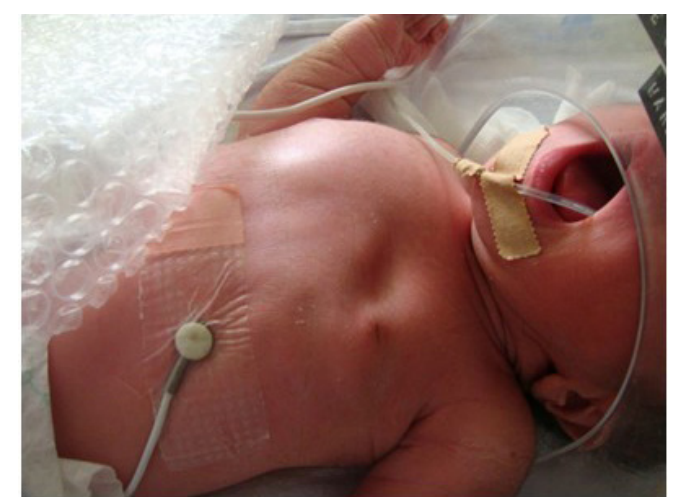

Figure 4 Infant showing hypoplasia of the left pectoral muscles and areola. On expiration intercostal recession is noted. (Reproduced from Lung herniation: an uncommon presentation of Poland's syndrome in a neonate at birth. Chandran S, et al. BMF Case Rep. 2013 Aug 6;2013, with permission from BMJ Publishing Group Ltd.).

association, which makes it an entity worth being aware of when investigating a suspected case of PS especially in infants with respiratory compromise. The association of eventration of diaphragm in PS could support SASDS, as the diaphragm is supplied in the embryonic phase by branches of the internal thoracic artery, a branch of subclavian artery (60). Hepatic exstrophy and wandering spleen have also been reported in PS $(61,62)$.

Dermatologic manifestations in PS include pectoral and axillary alopecia, anhidrosis and subcutaneous fat deficiency. Less often café-au-lait spots, cutaneous diffuse neurofibroma, congenital melanocytic nevus and congenital hemangiomas have been reported (63).

Increasing number of malignancies has been reported with PS, which includes leukemia, lymphoma, leiomyosarcoma, lung carcinoma, gastric carcinoma, and head and neck tumors. Huang et al. reported 2 cases of invasive ductal carcinoma of the ipsilateral breast in PS. A review of 21 cases of PS with breast cancer in the age range of 33 to 74 years showed pectoral involvement in all (64). The association of congenital anomalies or syndromes with malignancies is well known. This could be attributed to constitutional mutation of both proto-oncogenes and tumor-suppressor genes, which are known to cause congenital anomalies and neoplasms and many of the gene products play a critical role in signaling pathways, which control cellular proliferation (65).

Other rare congenital anomalies found to be associated with PS incorporate craniofacial dysplasia, microcephaly, Dandy-Walker malformation, and congenital cyanotic heart disease, partial anomalous pulmonary venous return (66). A spectrum of urogenital anomalies has been described with PS varying from hypospadias, duplication of collecting system to agenesis of the kidney (33). A case of coloboma of the optic disc, "Morning glory syndrome" was reported in a 12-year-old with classical PS (67). CHI has been described with PS phenotype in a newborn infant with duplication of the short arm of chromosome $10(25,32)$.

About $15 \%$ of patients with Moebius syndrome have features of PS (68). Moebius-Poland syndrome is estimated to have a prevalence rate of 1 in 500,000 live births. They have VI and VII cranial nerve palsies, upper and lower limb deformities, and pectoral muscle dysplasia (69). Sprengel's deformity (SD) has been shown to have an association with PS. It is a rare congenital disorder of pectoral girdle with elevation of scapula too high on one side of the body resulting in cosmetic and functional disability. Reported incidence of SD in PS is $15 \%$. Hypoplasia or absence of serratus anterior muscle, often affected in PS, results in varying degrees of elevation and medial winging of the scapula (42). Klippel-Feil syndrome characterized by the triad of a short neck, low posterior hairline, and limitation of neck movement is a rare congenital anomaly found in association with PS (70). It is caused by the fusion of cervical vertebrae. A common etiological theory, viz. the SASDS theory, has been postulated for Moebius, KlippelFeil and PS $(15,71)$.

It is important to mention that severity of manifestations 
in PS can vary significantly, as some patients present with very mild forms of chest wall hypoplasia that can be hard to identify especially at birth and usually are diagnosed later on in life. Cases with mild form of hand anomalies have been diagnosed near puberty when the limb asymmetry becomes more apparent.

\section{Classification of anomalies in PS}

As PS has widely variable expression and associated anomalies (Table 1), more than a few classifications of the syndrome were introduced by several authors over the years. The main objective of these classifications is to help surgeons decide about the need of surgical intervention and the extent of reconstructive surgeries. Seyfer et al. described two major forms of PS, a simple form and complex form, and this classification was according to the chest wall defect and did not take into consideration the hand anomalies. In the simple form, sterno-costal head of pectoralis major muscle is absent, and the ipsilateral axillary fold is lacking. If measured these patients have smaller hemithorax and ipsilateral upper limb. The breast and nipple-areola complex are smaller in the affected side. In contrast to the simple form, the complex form has a notably smaller hemithorax and ipsilateral limb hypoplasia sometimes with brachysyndactyly. In complex form, patients usually have an axillary web, rudimentary or absent breast and nipple-areola complex and shorter sternum and clavicle in the affected side (72). More recently, TBN (thorax, breast, nipple-areola complex) classification was proposed, aiming to include all possible phenotypes of PS (73).

A classification for limb abnormalities in PS has existed since 1984. Upper extremity anomalies with pectoral agenesis were classified into four types: presence of all digits and mitten hand in type 1 , to radial ray defects with absent thumb in type 4 (74). This was further modified to include all type of hand anomalies and was classified to seven types; from normal hand (type 1) to phocomelia (type 7) and also it has a grading system with increasing severity of hand defects (35).

\section{Diagnosis and evaluation of Poland syndrome}

Most cases of moderate to severe PS are diagnosed at birth when presented with visible chest or limb defects. Antenatal diagnosis using fetal ultrasound scan (US) can detect limb or thoracic defects. Doppler assessment of ipsilateral subclavian artery flow is recommended when unilateral skeletal defects are detected in fetal US. Three-dimensional US can aid in characterization of the limb defect (75). Further attempts of US evaluation for other known associated defects in PS should be made, facilitating explicit counseling of parents regarding fetal outcome. In high-risk families, fetal scan can pick up florid PS as early as the $12^{\text {th }}$ to $13^{\text {th }}$ gestational week even though CHILD syndrome (Congenital hemi-dysplasia with icthyosiform erythroderma and limb defects) can mimic PS especially in the absence of heart defects (76).

A clinical suspicion of PS arises on detection of chest defects \pm ipsilateral limb defect in a newborn infant or child. Many cases of PS have been diagnosed at various ages, and these may even present to the medical care for complaints not related to the syndrome itself. We can attribute this diverse age of diagnosis time to the wide spectrum of variation in severity of presentations, especially in those patients having simple PS with normal hands. Absence of anterior axillary fold is recognized in either sex with apparent PS. Female deformity can vary from breast hypoplasia to amastia. Associated ipsilateral thoracic and limb defects upstage the diagnosis to a severe form of PS. Mild forms like isolated syndactyly warrants a thorough examination as $10 \%$ of these cases will have PS. Abnormal dermatoglyphic patterns have been described and may supplement to make a diagnosis of PS (53).

Imaging modalities are crucial for diagnosis and it has an essential role in detecting the specific location and characteristics of the chest wall deformity. The chest X-ray usually shows lung field hyperlucency in the affected side, which according to the literature looks like "a post radical mastectomy picture". Both the CT and the MRI are used to enable accurate diagnosis, to show the extent of lesions in the musculo-skeletal component, and to help in the surgeon's decision regarding the best modalities for reconstruction. Some authors endorse the 3D CT as it demonstrates the extent of the deformity and tissue hypoplasia in the most accurate way, which helps with planning for transposition of muscular flaps and reconstructive techniques (77). Preoperative angiography is essential to assess the local vascular integrity before planned microvascular tissue transfer (78). PS was first accidentally noted when coexisting pectoral hypoplasia was detected in mammogram (36). It is also important to assess the pulmonary function, facilitating surgical decision on the need for intervention in cases of paradoxical movement of the chest wall and restrictive lung disease (79).

\section{Surgical intervention and reconstruction}

Most of the defects seen in PS are of the simple type with 
Table 1 Spectrum of anomalies seen in Poland's syndrome

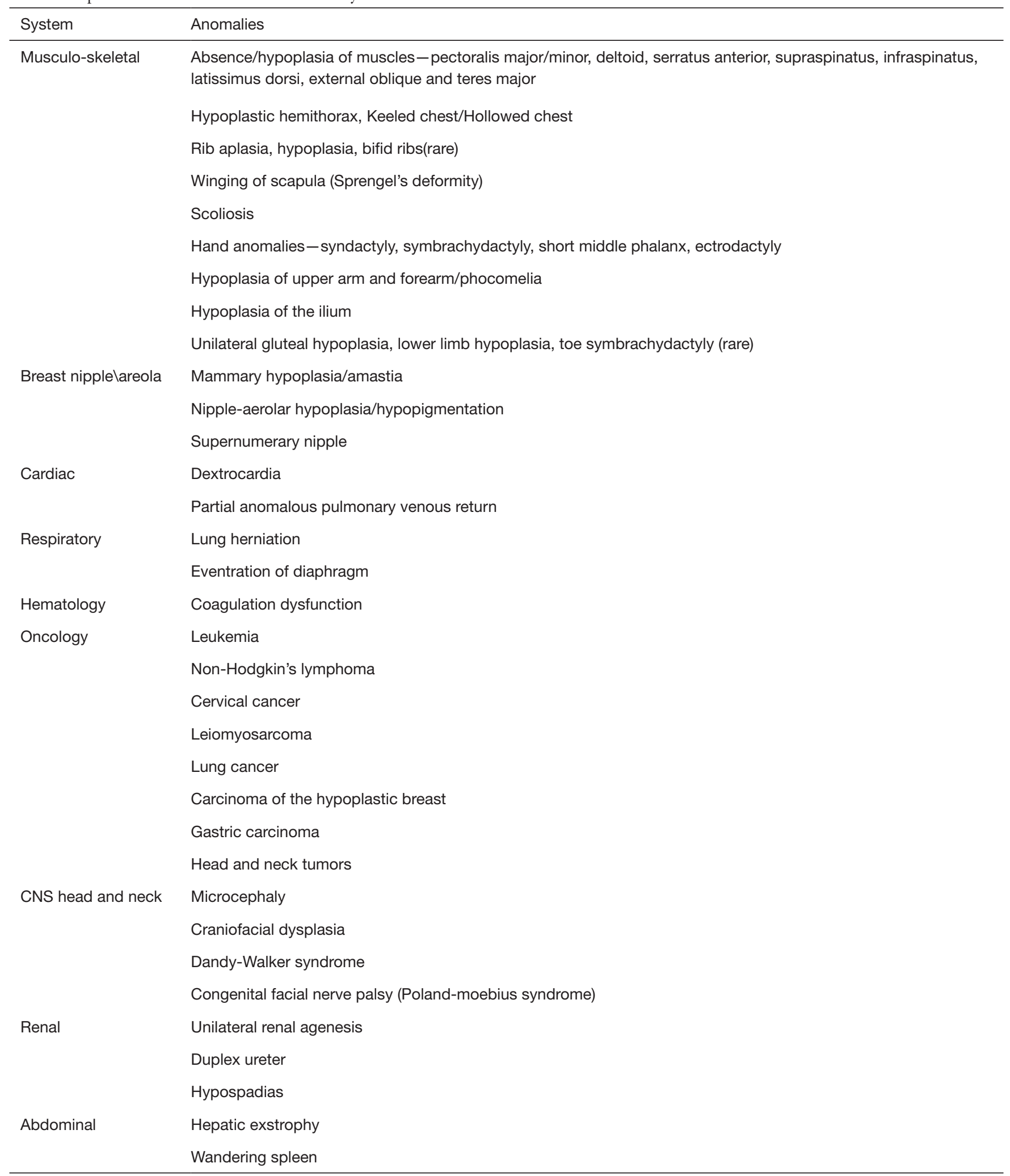

Table 1 (continued) 
Table 1 (continued)

\begin{tabular}{ll}
\hline System & Anomalies \\
\hline Dermatological & Anhidrosis \\
& Ipsilateral alopecia of the pectoral and axillary areas \\
& Café au lait spots \\
& Cutaneous hemangioma \\
& Cutaneous neurofibroma \\
& Congenital melanocytic nevus \\
& Dermatoglyphic abnormalities \\
& Coloboma of the optic disc (morning glory syndrome) \\
Eye & Congenital hyperinsulinism \\
Endocrine & Klippel-Feil syndrome \\
\hline
\end{tabular}

CNS, central nervous system.

mild functional disabilities. Cosmesis remains the most common indication for repair. Unless there is significant respiratory compromise, chest deformities may not need any intervention in early life. The vital capacity of the lung can be as low as $48 \%$ depending on the severity of the disease and may increase up to $68 \%$ after surgical correction (80). We reported a case of PS with significant lung herniation in neonatal life through the left sided rib defect, which regressed spontaneously and remained stable without any intervention when last reviewed at 6 years of age (4) (Video 1).

Generally, surgical intervention may be required for the following indications in PS (3):

(I) Unilateral depression of the chest wall with possible progression with age.

(II) Inadequate protection of the lung and heart.

(III) Paradoxical movement of the chest wall.

(IV) Hypoplasia or aplasia of the breast in females.

(V) Improvement of aesthetic appeal of the chest contour due to lack of pectoralis major muscle and anterior axillary fold in males.

Reconstructive procedures may be required for both chest deformity and limb defects in adolescence. Unilateral depression of the chest wall with severe aplasia of the ribs needs correction in two stages; rib defect repair followed by muscle flap transposition. The most used techniques are the latissimus dorsi flap, or the rectus abdominis flap if the latissimus dorsi is absent as a part of the syndrome. The surgical reconstruction should be tailored according to each patient's condition and satisfaction with the results. In female patients, mammoplasty may be carried out with muscle flap transposition $(20,72)$.

Stem cell therapy has shown some promise in correction of chest defects and breast augmentation. A 23-year-old female with PS had a successful reconstruction of breast by increasing the density of adipose derived stem cells following two local injections of autologous fat cells (81). Lately, a 28-year-old-male with severely affected right chest due to PS had restoration of pectoral area with injections of adipose-derived mesenchymal stem cells and fat transfer (82). The proposed mechanisms involved in the role of stem cell transfer include adipose derived stem cells contributing to neoangiogenesis in the acute phase by functioning as endothelial progenitor cells or as angiogenicfactor-releasing cells. The injected fat cells trigger stem cell differentiation within the affected area. So, stem cell therapy could contribute to vascular and muscle growth $(83,84)$.

Reconstructive surgery for limb/hand anomalies aim to provide a functional hand in PS and it depends greatly on the nature of the deformity. Corrective surgery should be planned at an optimal time for symbrachydactyly before flexion contractures and angular deformity sets in. Rarely, corrective osteotomies are required for misaligned joints of the upper extremity to give a functional hand $(85,86)$.

In summary, the reconstructive surgeries in the chest wall are mostly for cosmetic purposes and any functional disability in PS is usually caused by the syndactyly of the hand. Most patients with PS lead a normal life and hardly have any functional limitations. Surgical intervention is usually delayed to adolescence, as the correction is mostly 
cosmetic, especially in females, unless the patient present with severe symptoms that require early intervention. Consensus is that delaying the intervention is better as the patient will have an opportunity to make decision regarding the correction, and also to avoid the need for surgical revision with growth (72).

\section{Genetic counseling}

Presentation of PS in infancy and early childhood is minimal due to the subtle nature of the pectoral and limb hypoplasia. The actual incidence in the population could be still underestimated (13). New modalities of imaging like CT/MRI and mammogram are picking up more cases of minor pectoral and limb defects when investigated for other reasons. A detailed examination of the proband's firstdegree relatives focusing on minor hand and/or pectoral defects and dermatoglyphics may unmask a hidden PS phenotype $(52,53)$. If positive evidence of PS is found, one may envision a risk of $50 \%$ in the offspring (68). The few familial cases described in the literature had significant intrafamilial phenotypic heterogeneity, but this indicates some degree of genetic influence $(26,28,87)$. Current evidence is insufficient to provide a good genetic etiology for PS and this supports David's conclusion that "Poland's anomaly can be regarded as a sporadic condition with an extremely low recurrence risk" (88).

\section{Conclusions}

Historical aspects leave a heated debate on the eponymous origin of PS as several authors have described these paired defects prior to Alfred Poland. This review highlights the various theories related to the genesis of PS. Partial or full absence of the pectoralis major muscle is mandatory to make the diagnosis. PS has very versatile presentations and many systemic associations. Since it was first diagnosed almost two centuries ago, more associations have been added, and different and unusual presentations included. An extensive spectrum of anomalies described in PS till date is included in this review. One may conclude that surgical intervention is generally done in adolescence mostly for cosmesis but may rarely be needed to improve restrictive lung diseases in severe chest wall defects.

We recommend establishing a PS data registry with systematically collected phenotypic data of affected patients. The registry will serve to improve knowledge of this rare musculo-skeletal disorder and facilitate epidemiological studies. Further, establishing an effectual information network will promote research and clinical collaboration, in turn enhancing the quality of life of patients with varied forms of PS.

\section{Acknowledgments}

We thank Prof. Divakaran Liginlal, Carnegie Mellon University, Pittsburgh, Pennsylvania, USA and Dr. Krishna Revanna Gopagondanahalli, Staff Physician, KK Women's and Children's Hospital, Singapore for editing the manuscript. Funding: None.

\section{Footnote}

Reporting Checklist: The authors have completed the Narrative Review reporting checklist. Available at http:// dx.doi.org/10.21037/tp-20-320

Conflicts of Interest: All authors have completed the ICMJE uniform disclosure form (available at http://dx.doi. org/10.21037/tp-20-320). The authors have no conflicts of interest to declare.

Ethical Statement: The authors are accountable for all aspects of the work in ensuring that questions related to the accuracy or integrity of any part of the work are appropriately investigated and resolved. Written informed consent was obtained from the parents of the child for publication of the images. Published figures and video are reproduced with permission from publisher.

Open Access Statement: This is an Open Access article distributed in accordance with the Creative Commons Attribution-NonCommercial-NoDerivs 4.0 International License (CC BY-NC-ND 4.0), which permits the noncommercial replication and distribution of the article with the strict proviso that no changes or edits are made and the original work is properly cited (including links to both the formal publication through the relevant DOI and the license). See: https://creativecommons.org/licenses/by-nc-nd/4.0/.

\section{References}

1. Poland A. Deficiency of the pectoral muscles. Guys Hosp Rep 1841;6:191-3.

2. Clarkson P. Poland's syndactyly. Guys Hosp Rep 1962;111:335-6. 
3. Fokin A A, Robicsek F. Poland's syndrome revisited. Ann Thorac Surg 2002;74:2218-25.

4. Chandran S, Revanna KG, Ari D, et al. Lung herniation: an uncommon presentation of Poland's syndrome in a neonate at birth. BMJ Case Rep 2013;2013:bcr2013200106.

5. Garreau MF. Procès-verbaux du 12 frimaire an 12 jusques au 1er fructidor an 12. Société Anatomique de Paris, Paris, 1996:42.

6. Charlier P, Deo S, Galassi FM, et al. Poland syndrome before Alfred Poland: the oldest medical description (Paris, France, 1803). Surg Radiol Anat 2019;41:1117-8.

7. Lallemand LM. Absence de trois côtes simulant un enfoncement accidentel. Éphémérides Médicales de Montpelier 1826;1:144-7.

8. Froriep R. Beobachtungeines Falles von Mangel der Brustdruse. Notizen Ausdem Gebiete der Natur und Heilkinde 1839;10:9-14.

9. Brown JB, McDowell F. Syndacylism with absence of Pectoralis Major. Surgery 1940;7:599-601.

10. McDowell F. On the Propagation, Perpetuation, and Parroting of Erroneous. Eponyms Such as "Polands syndrome”. Plast Reconstr Surg 1977;59:561-3.

11. Thompson J. On a Form of Congenital Thoracic Deformity. Teratologia 1895;2:1-12.

12. Baudinne P, Bovy GL, Wasterlain A. Uncas de syndrome de Poland. Acta Paediatr Belg 1967;21:407-10.

13. Ram AN, Chung KC. Poland's syndrome: current thoughts in the setting of a controversy. Plast Reconstr Surg 2009;123:949-53.

14. Van Allen MI. Fetal vascular disruptions: Mechanisms and some resulting birth defects. Pediatr Ann 1981;10:219-33.

15. Bavinck JNB, Weaver DD. Subclavian artery supply disruption sequence: Hypothesis of a vascular etiology for Poland, Klippel-Feil, and Mobius anomalies. Am J Med Genet 1986;23:903-18.

16. Merlob P, Schonfeld A, Ovadia Y, et al. Real-time echoDoppler Duplex Scanner in the evaluation of patients with Poland sequence. Eur J Obstet Gynecol Reprod Biol 1989;32:103-8.

17. Silengo M, Lerone M, Seri M, et al. Lower extremity counterpart of the Poland syndrome. Clin Genet 1999;55:41-3.

18. Atasoy HI, Yavuz T, Altunrende S, et al. A unique case of right-sided Poland syndrome with true dextrocardia and total situs Inversus. Eur J Pediatr 2013;172:269-72.

19. Hoyme HE, Jone KL, Van Allen MI, et al. Vascular pathogenesis of transverse limb reduction defects. J Pediatr
1982;101:839-43.

20. Cingel V, Bohac M, Mestanova V, et al. Poland syndrome: from embryological basis to plastic surgery. Surg Radiol Anat 2013:35:639-46.

21. Congdon ED. Transformation of the aortic-arch system during the development of the human embryo. Carnegie Institution Washington Contributions to Embryology 1922;14:47-113.

22. Puvabanditsin S, Garrow E, Augustin G, et al. PolandMöebius syndrome and cocaine abuse: A relook at vascular etiology. Pediatr Neurol 2005;32:285-7.

23. Martínez-Frías ML, Czeizel AE, Rodriguez-Pinilla E, et al. Smoking During Pregnancy and Poland sequence: Results of a Population-based Registry and a Case-control registry. Teratology 1999;59:35-8.

24. Ferraro GA, Perrotta A, Rossano F, et al. Poland syndrome: Description of an atypical variant. Aesthetic Plast Surg 2005;29:32-3.

25. PinneySE, Ganapathy K, BradfieldJ, et al. Dominant form of congenital hyperinsulinism maps to HK1 region on $10 \mathrm{q}$. Horm Res Paediatr 2013;80:18-27.

26. Vaccari CM, Romanini MV, Musante I, et al. De novo deletion of chromosome 11q12.3 in monozygotic twins affected by Poland Syndrome. BMC Med Genet 2014;15,63.

27. Bamforth JS, Fabian C, Machin G, et al. Poland anomaly with a limb body wall disruption defect: case report and review. Am J Med Genet 1992;43:780-4.

28. Darian VB, Argenta LC, Pasyk KA. Familial Poland's syndrome. Ann Plast Surg 1989;23:531-37.

29. Fraser FC, Ronen GM, O'Leary E. Pectoralis major defect and Poland sequence in second cousins: extension of the Poland sequence spectrum. Am J Med Genet 1989;33:468-70.

30. Happle R. Poland anomaly may be explained as a paradominant trait. Am J Med Genet 1999;87:364-5.

31. Lowry RB, Bouvet JP. Familial Poland anomaly. J Med Genet 1983;20:152-4.

32. Giri D, Patil P, Hart R, et al. Congenital hyperinsulinism and Poland syndrome in association with 10p13-14 duplication. Endocrinol Diabetes Metab Case Rep 2017;2017:16-0125.

33. Hegde HR, Leung AKC. Aplasia of Pectoralis Major Muscle and Renal Anomalies. Am J Med Genet 1989;32:109-11.

34. Stewart FJ, Boston VE. Poland Anomaly With a Limb Body Wall Disruption defect. Am J Med Genet $1993 ; 46: 350$.

35. Al-Qattan MM. Classification of hand anomalies in 
Poland's syndrome. Br J Plast Surg 2001;54:132-6.

36. Perez Aznar JM, Urbano J, Garcia Laborda E, et al. Breast and pectoralis muscle hypoplasia. A mid degree of Poland's syndrome. Acta Radiol 1996;37:759-62.

37. Van Allen MI, Hoyme HE, Jones KI. Vascular pathogenesis of limb defects. Radial artery anatomy in radial aplasia. J Pediatr 1982;101:832-8.

38. Gilley E. Absence incomplete de mammelles chez une femme mere. Atrophie de Member supèerieur droit. Courrier Mèd 1882;32:27.

39. Baban A, Torre M, Bianca S. Poland Syndrome with Bilateral Features: Case Description with Review of the Literature. Am J Med Genet 2009;149A:1597-602.

40. Walker JC Jr, Meijer R, Aranda D. Syndactylism with deformity of the pectoralis muscle. Poland's syndrome. J Pediatr Surg 1969;4:569-72.

41. Caouette-Laberge L, Borsuk D. Congenital Anomalies of the Breast. Semin Plast Surg 2013;27:36-41.

42. Yiyit N, Isitmangil T, Oksuz S. Clinical analysis of 113 patients with Poland syndrome. Ann Thorac Surg 2015;99:999-1004.

43. Torre M, Baban A, Buluggiu A, et al. Dextrocardia in patients with Poland syndrome: phenotypic characterization provides insight into the pathogenesis. J Thorac Cardiovasc Surg 2010;139:1177-82.

44. Powell CV, Coombs RC, David TJ. Poland anomaly with contralateral ulnar Ray defect. J Med Genet 1993;30:423-4.

45. Shamberger RC, Welch KJ, Upton J 3rd. Surgical treatment of thoracic deformity in Poland's syndrome. J Pediatr Surg 1989;24:760-5.

46. Gocmen H, Akkas Y, Doganay S. Poland syndrome: rare presentation in two cases. N Z Med J 2010;123:71-7.

47. Mace JW, Kaplan JM, Schanberger JE, et al. Poland's syndrome. Report of seven cases and review of the literature. Clin Pediatr (Phila) 1972;11:98-102.

48. Hamidu AU, Musa A, Tahir MC. Poland's syndrome: an incidental finding on routine medical examination. Nigerian Journal of Surgical Research 2006;8:97-8.

49. David TJ. Nature and etiology of the Poland anomaly. N Engl J Med 1972;287:487-9.

50. David TJ, Saad MN. Dermatoglyphic diagnosis of the Poland anomaly in the absence of syndactyly. Hum Hered 1974;24:373-8.

51. Gnamey D. The finger print diagnosis of Poland's syndrome without syndactylia. J Genet Hum 1976;24:201-5.

52. Freire-Maia N, Chautard EA, Opitz JM, et al. The Poland Syndrome - Clinical and Genealogical Data, Dermatoglyphic Analysis, and Incidence. Hum
Hered1973;23:97-104.

53. Atasu M. Dermatoglyphic findings in Poland's syndrome. J Med Genet 1980;17:50-2.

54. Agarwal S, Arya A. Poland's syndrome. Indian J Dermatol Venereol Leprol 2008;74:62-3.

55. Corona-Rivera JR, Corona-Rivera A, Totsuka-Sutto SE, et al. Corroboration of the lower extremity counterpart of the Poland sequence. Clin Genet 1997;51:257-9.

56. Riccardi VM. Unilateral gluteal hypoplasia and brachysyndactyly: lower extremity counterpart of the Poland anomaly. Pediatrics 1978;61:653-4.

57. Gonda K, Tachiya Y, Hatakeyama Y, et al. Poland syndrome accompanied by internal iliac artery supply disruption sequence: A case report. J Med Case Rep 2018;12:312.

58. Ravitch, MM. Poland's syndrome. In Congenital deformities of the chest wall and their operative correction. Philadelphia, London, Toronto: WB Saunders; 1977:233-71.

59. Warkany J. Congenital malformations: Notes and comments. Chicago: Yearbook 58. Medical Publ Inc; 1971. doi.org/10.1002/tera.1420060226.

60. Shahrul Baharin N, Awadh Hashim E, Bin Huey Q, et al. Reinforcing the vascular disruption theory of the genesis of Poland's syndrome: A rare association of diaphragmatic eventration in a preterm infant with severe musculoskeletal defects. BMJ Case Rep 2021;14:e238392.

61. Puder M, Green A, Mooney D. Hepatic exstrophy complicating Poland's anomaly. J Pediatr Surg 2002;37:1203-4.

62. Kulkarni ML, Sneharoopa B, Vani HN, et al. Eventration of the diaphragm and associations. Indian J Pediatr 2007;74:202-5.

63. Vazirnia A, Cohen PR. Poland's syndrome: A Concise Review of the Clinical Features Highlighting Associated Dermatologic Manifestations. Am J Clin Dermatol 2015;16:295-301.

64. Huang Y, Pang H, Jin S, et al. Clinical characteristics of Poland's syndrome associated with breast cancer: Two case reports and a literature review. J Cancer Res Ther 2018;14:1665-9.

65. Friedman JM. Genetics and epidemiology, congenital anomalies and cancer. Am J Hum Genet 1997;60:469-73.

66. Konar MC, Sil A, Das A, et al. Poland syndrome with some rare associations, and brief literature review. Indian Journal of Case Reports 2018;4:61-3.

67. Pisteljić DT, Vranjesevic D, Apostolski S, et al. Poland syndrome associated with "morning glory" syndrome. J Med Genet 1986;23:364-6. 
68. Kuklík M. Poland-Mobius syndrome and disruption spectrum affecting the face and extremities: a review paper and presentation of five cases. Acta Chirurgiae Plasticae 2000;42:95-103.

69. Parker DL, Mitchell PR, Holmes GL. Poland-Moebius syndrome. J Med Genet 1981;18:317-20.

70. Erol M, Casken H, Tan O, et al. Report of a girl with Klippel-feil Syndrome and Poland anomaly. Genet Couns 2004:15:469-72.

71. Issaivanan M, Virdi VS, Parmar VR. Subclavian Artery Supply Disruption Sequence- Klippel-Feil and Mobius Anomalies. Indian J Pediatr 2002;69:441-2.

72. Seyfer AE, Fox JP, Hamilton CG. Poland Syndrome: Evaluation and Treatment of the Chest Wall in 63 Patients: Plast Reconstr Surg 2010;126:902-11.

73. Romanini MV, Torre M, Santi P, et al. Proposal of the TBN Classification of Thoracic Anomalies and Treatment Algorithm for Poland Syndrome. Plast Reconstr Surg 2016;138:50-8.

74. Gausewitz SH, Meals RA, Setoguchi Y. Severe limb deficiency in Poland's syndrome. Clin Orthop Relat Res 1984;185:9-13.

75. Berdel AL, Henrich W. Antenatal sonographic features of Poland syndrome on 2- and 3-dimensional sonography. J Ultrasound Med 2010;29:679-80.

76. Paladini D, D'Armiento M, Martinelli P. Prenatal Ultrasound Diagnosis of Poland Syndrome. Obstet Gynecol 2004;104:1156-9.

77. Ribeiro RC, Saltz R, Mangles MGM, et al. Clinical and Radiographic Poland Syndrome Classification: A Proposal. Aesthet Surg J 2009;29:494-504.

Cite this article as: Hashim EAA, Quek BH, Chandran S. A narrative review of Poland's syndrome: theories of its genesis, evolution and its diagnosis and treatment. Transl Pediatr 2021;10(4):1008-1019. doi: 10.21037/tp-20-320
78. Beer GM, Hergan PK. Poland's Syndrome and Vascular Malformations. Br J Plast Surg 1996;49:482-4.

79. Arango Tomás E, Baamonde Laborda C, Algar Algar J, et al. Chest Wall Reconstruction with Methacrylate Prosthesis in Poland Syndrome. Archivos de Bronconeumologia 2013;49:450-2.

80. Martin L W, Helmsworth JA. The Management of Congenital Deformities of the Sternum. JAMA 1962;179:82-4.

81. Yang H, Lee H. Successful Use of Squeezed-Fat Grafts to Correct a Breast Affected by Poland Syndrome. Aesthetic Plast Surg 2011;35:418-25.

82. Christopoulos A, Ligoudistianou C, Bethanis P, et al. Successful use of adipose-derived mesenchymal stem cells to correct a male breast affected by Poland Syndrome: a case report. J Surg Case Rep 2018;2018:rjy151.

83. Miranville A, Heeschen C, Sengenès C, et al. Improvement of postnatal 82 . neovascularization by human adipose tissue-derived stem cells. Circulation 2004;110:349-55.

84. Rehman J, Traktuev D, Li J, et al. Secretion of angiogenic and 83 . antiapoptotic factors by human adipose stromal cells. Circulation 2004;109:1292-8.

85. Ireland DC, Takayama N, Flatt AE. Poland's syndrome. J Bone Joint Surg 1976;58:52-8.

86. Buckwalter VJA, Shah AS. Presentation and Treatment of Poland Anomaly. Hand (N Y) 2016;11:389-95.

87. Parano E, Falsaperla R, Pavone V, et al. Intrafamilial Phenotypic Heterogeneity of the Poland Complex: A Case report. Neuropediatrics 1995;26:217-9.

88. David TJ. Familial Poland anomaly. J Med Genet 1982;19:293-6. 